\title{
COMENTÁRIO EDITORIAL \\ A REVISTA IBERO-AMERICANA DE ESTRATÉGIA EM 2016 E 2017
}

Nestes últimos dois anos a Revista IberoAmericana de Estratégia (RIAE) - Iberoamerican Journal of Strategic Management (IJSM) tem procurado aprimorar e consolidar as mudanças realizadas desde 2014. Este movimento não poderia acontecer sem que os autores, a quem agradecemos, apesar das diversas alternativas de periódicos onde submeter os seus trabalhos, tenham escolhido a RIAE/IJSM. Também não seria possível sem o esforço e dedicação dos revisores. Agradecemos aos nossos revisores, não só pela dedicação, mas pelo esforço que têm feito em melhorar a qualidade das revisões e apontar possibilidades de melhoria, mesmo para os artigos que por ventura não sejam aceitos.

A equipe editorial da UNINOVE, possibilitou o progresso da revista e com esforço para melhorar o processo editorial e acelerar a publicação. Vai um agradecimento especial para a Camila de Oliveira
Fernando Antonio Ribeiro Serra Editor Científico RIAE

Universidade Nove de Julho - UNINOVE

Programa de Pós-Graduação em Administração

\section{Manuel Aníbal Silva Portugal Vasconcelos Ferreira Editor Adjunto RIAE \\ Universidade Nove de Julho - UNINOVE Programa de Pós-Graduação em Administração}

Prado e ao Altiéres de Oliveira Silva pela inestimável ajuda, esforço e sugestões para o aprimoramento. Agradeço o apoio da UNINOVE por intermédio do Prof. Emerson Maccari, diretor do PPGA e que nos tem apoiado de forma incondicional nas mudanças, bem como à equipe da Biblioteca que passou a ter sob sua tutela a equipe editorial.

No comentário editorial deste primeiro número de 2018, apresentamos dados e informações que mostram a evolução da RIAE/IJSM. Com este relatório bianual prestamos conta do nosso trabalho aos leitores, autores e revisores do periódico. A RIAE/IJSM manteve o seu status Qualis B2 e continuamos a trabalhar para elevar este nível no futuro possível. Hoje a RIAE/IJSM é o $17^{\circ}$ periódico em impacto no Spell, base de periódicos da ANPAD na qual estão os periódicos nacionais. 


\section{Evolução recente da Revista Ibero-Americana de Estratégica}

Apresentamos alguns dados que refletem parte o progresso da RIAE entre 2014 e 2017 . A quantidade de submissões reduziu a partir em 2017. Em parte, imputamos a que explicitamos mais claramente o escopo da RIAE/IJSM. O efeito é uma redução da reprovação pelo editor.
Na nossa avaliação como editores, a qualidade dos artigos submetidos tem melhorado. Os avaliadores aumentaram o nível de exigência, o que aumentou a carga de trabalho dos autores nas revisões de seus artigos. Os avaliadores continuam fazendo revisões construtivas e mais extensas. $\mathrm{O}$ índice de rejeição de artigos, ainda assim, foi de $78 \%$ em 2016 e $65 \%$ em 2017.

Tabela 1 - Dados de submissão da RIAE de 2016 a 2017

\begin{tabular}{|c|c|c|}
\hline ANO & $\mathbf{2 0 1 6}$ & $\mathbf{2 0 1 7}$ \\
\hline PERIODICIDADE & \multicolumn{2}{|c|}{} \\
\hline $\begin{array}{c}\text { Artigos submetidos no } \\
\text { sistema }\end{array}$ & 175 & 115 \\
\hline Desk Reject & $85(48,57 \%)$ & $45(39,13 \%)$ \\
\hline $\begin{array}{c}\text { Artigos avaliados Double } \\
\text { Blind }\end{array}$ & 90 & 70 \\
\hline \% Artigos aceitos & $42,22 \%$ & $57,14 \%$ \\
\hline Artigos publicados & 38 & 40 \\
\hline Rejeição total & $78,29 \%$ & $65,22 \%$ \\
\hline
\end{tabular}

Apesar da quantidade de artigos em estoque para publicar, os artigos estão sendo publicados em até 6 meses depois da submissãoPela quantidade de submissões em relação à exigência dos avaliadores, o prazo parece estar adequado para um periódico B2 ou B1. De certa forma, os prazos de avaliação são impactados pelas férias de final de ano e pelo trabalho adicional dos avaliadores nos períodos de congressos nacionais e internacionais, além de outros periódicos. No intuito de reduzir o prazo de avaliação, estamos cadastrando e testando novos avaliadores.

Tabela 2 - Tempos de avaliação e submissão

\begin{tabular}{|c|c|c|}
\hline ANO & $\mathbf{2 0 1 6}$ & $\mathbf{2 0 1 7}$ \\
\hline Tempo de avaliação (dias) & 87 & 107 \\
\hline Tempo de publicação (dias) & 182 & 160 \\
\hline
\end{tabular}

A quantidade de usuários cadastrados tem aumentado significativamente desde 2013. Isto pode ser verificado pela quantidade de usuários novos. O aumento da quantidade de usuários reflete o impacto das novas seções. Os comentários editoriais, por exemplo, têm sido bastante acessados. Estes comentários têm sido arquivados na aba How to publish (or Perish?) no site da RIAE, ficando assim disponíveis para consulta (ver em: http://www.revistaiberoamericana.org/ojs/index.php/ib ero/pages/view/publish\%20or\%20perish).
Eles apresentam sugestões para que pesquisadores menos experientes possam melhorar a qualidade de seus artigos. Além dos artigos e da perspectiva, temos publicado um artigo tecnológico por edição, que apresentam aplicações voltadas para a prática. Uma outra mudança foi o fato de termos agora resenhas de livros importantes, mais extensas e que ajudam alunos em seus estudos e em conhecer livros clássicos e relevantes que costumam aparecer citados em artigos. 
Tabela 3 - Evolução dos usuários cadastrados

\begin{tabular}{|l|c|c|}
\hline \multicolumn{1}{|c|}{ ANO } & $\mathbf{2 0 1 6}$ & $\mathbf{2 0 1 7}$ \\
\hline Usuários cadastrados & 19713 & 32780 \\
\hline Usuários novos & 14710 & 13067 \\
\hline
\end{tabular}

A submissão de artigos e, em especial, a busca por artigos publicados na RIAE tem aumentado por pesquisadores nacionais e estrangeiros. Praticamente triplicou em dois anos. Dentre outros fatores: a divulgação da revista pelo canal da Iberoamerican Academy of Management, a tradução do site para o idioma inglês e do título da revista (Iberoamerican
Journal of Strategic Management), da divulgação maior em congressos nacionais e internacionais, na participação em mídias sociais e por ter crescido o número de artigos publicados na RIAE em inglês e espanhol. A Tabela 4 apresenta os acessos por país de origem em 2018, considerando que eram incipientes nos anos anteriores.

Tabela 4 - Acessos por país aos artigos da RIAE

\begin{tabular}{l|r|r}
\multicolumn{1}{c|}{ País } & Usuários & \multicolumn{1}{c}{$\%$} \\
\hline Brasil & 20890 & 65,71 \\
\hline EUA & 1686 & 5,25 \\
\hline Reino Unido & 1054 & 3,30 \\
\hline Portugal & 698 & 2,19 \\
\hline México & 677 & 2,12 \\
\hline Índia & 551 & 1,73 \\
\hline China & 356 & 1,12 \\
\hline Espanha & 323 & 1,01 \\
\hline Alemanha & 272 & 0,85 \\
\hline Australia & 255 & 0,8 \\
\hline Total & 31857 & \\
\hline
\end{tabular}

Fonte: Google Analytics, 2018.

Outro indicador importante do crescimento do impacto da RIAE é o da base Spell. A RIAE está no primeiro quartil dos periódicos que compõem a base (http://www.spell.org.br/impacto). Não descuidamos da relevância que é, em primeira instância, o interesse dos pesquisadores nos artigos que temos publicado. $\mathrm{O}$ melhor indicador deste interesse é o crescimento do número de downloads e de citações aos artigos em outras bases.

\section{A continuidade do trabalho}

Continuamos com o sonho de ter uma RIAE/IJSM de impacto internacional. Para isto, no entanto, precisaremos de mais recursos materiais e de maior esforço de autores e avaliadores. Nosso caminho também passa por conseguir melhorar a relevância na base Spell.

Pretendemos continuar a trabalhar com os revisores para termos cada vez mais e melhores avaliações construtivas, sem aumentar o tempo de avaliação e publicação. Continuamos com a orientação de contribuir para a ciência em Administração brasileira, especialmente em estratégia.

Continuaremos com os comentários editoriais voltados para o aprimoramento da qualidade dos artigos, agora com mais foco sobre os métodos. Com os comentários editoriais pretendemos melhorar a qualidade de nossos artigos e até mesmo de outros periódicos. Esperamos que possam também contribuir como material de aulas e workshops voltados para alunos.

Defendemos a crescente orientação para a pesquisa voltada a fenômenos, em especial por estarmos em um ambiente institucional distinto dos países mais desenvolvidos. Continuamos a alertar que esta orientação necessita ser ponderada com o foco teórico, seguindo os melhores padrões internacionais.

A RIAE/IJSM continua a aceitar todo o tipo de artigos, desde que a metodologia seja adequada, ajustada ao que se estuda e bem executada.

Adicionalmente, ao longo dos anos a RIAE tem apoiado encontros e congressos de administração, para que trabalhos selecionados possam seguir em fast track. O fast track não implica aceitação do artigo, mas 
apenas um processo que a equipe editorial acompanha para ser mais rápido.

Em 2018 iniciamos um canal de YouTube, nada mais prático que uma Teoria. O canal visa divulgar nossas pesquisas de forma mais prática para o público em geral nas redes sociais, especialmente no LinkedIn e no Facebook. Em breve, estaremos incentivando aos autores a participarem do canal.

Continuamos a sonhar em ter um dia os artigos publicados em português, espanhol e inglês no website.
Embora tenha crescido a publicação de artigos em idioma estrangeiro, acreditamos que ter uma versão do texto em português é importante.

Agradecemos a todos que têm apoiado e ajudado no desenvolvimento da RIAE. É nossa intenção continuar seguindo na busca de tornar A RIAE/IJSM mais influente e relevante para a academia nacional e como veículo de divulgação da pesquisa brasileira em estratégia. 